Florida International University FIU Digital Commons

$11-22-1995$

\title{
The relationship between Common Language and Length of Treatment in Occupational Therapy
}

Nivia Liz Binett

Florida International University

DOI: $10.25148 /$ etd.FI14051154

Follow this and additional works at: https://digitalcommons.fiu.edu/etd

Part of the Occupational Therapy Commons

\section{Recommended Citation}

Binett, Nivia Liz, "The relationship between Common Language and Length of Treatment in Occupational Therapy" (1995). FIU Electronic Theses and Dissertations. 1679.

https://digitalcommons.fiu.edu/etd/1679 


\section{FLORIDA INTERNATIONAL UNIVERSITY}

MIAMI, FLORIDA

The Relationship Between Common Language and Length of Treatment in Occupational Therapy

A thesis submitted in partial satisfaction of the requirement for the degree of Masters of Science in Occupational Therapy

by

Nivia Liz Binett

1995 
To: Judith Blucker

College of Health

This thesis, is written by Nivia L. Binett and entitled The Relationship Between Common Language and Length of Treatment in Occupational Therapy, having been approved in respect to and style and intellectual content, is referred to you for judgement.

We have read this thesis and recommend that it be approved.

Reba L. Anderson

Jyoti Zalkikar

Patricia J. Scott

Major Professor

Date of Defense: November 22, 1994

The thesis of Nivia Liz Binett is approved

Dean Judith Blucker

College of Health

Dr. Rilchard L. Campbell

Dean of Graduate Studies

Florida International University, 1995 
COPYRIGHT 1995 by Nivia L. Binett

Al1 rights reserved 
I dedicate this thesis to Nuris, Mabel, Yvonne, Alfonso, Tito and Lamont, my loving family, for without their support this task would have been impossible. 


\section{ACKNOWLEDGMENTS}

Special thanks to Janie Escobar and the occupational therapy department at Jackson Memorial Hospital for all of your support in making this project possible. 


\section{ABSTRACT OF THE THESIS}

The Effects of Language on Length of Treatment in Occupational Therapy

by

Nivia Liz Binett

Florida International University, 1994

Miami, Florida

Professor Patricia J. Scott, Major Professor

The diversity of ethnic and cultural groups and the effects of language in the therapeutic relationship are timely professional issues of concern to occupational therapy practitioners. The tri-ethnic, tri-cultural South Florida area offers a natural environment where one can study how patient-therapist interactions are influenced by language barriers in a diverse society. This study examines the effects of language on the adequacy of occupational therapy services, specifically how language affects the length of the treatment program. The nature of diagnosis therapists' ethnicity, and how they impact treatment outcomes are also addressed. A sample was drawn from the occupational therapy outpatient department of a large county hospital. Data taken from patients' charts examined race, sex, age, diagnosis, and language. Number of treatment sessions and length of treatment were viewed as proxy measures for adequacy. Findings indicate that the effect of language cannot be understood aside from ethnicity. Implications for occupational therapy practice are discussed. 
CHAPTER I

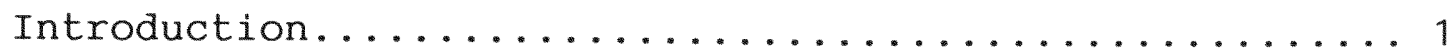
How does cultural diversity affect health care?....... 1 Ethnic variation.......................... 4 Significance of study..................... 5

CHAPTER II

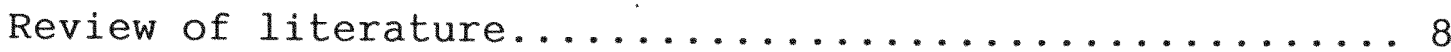

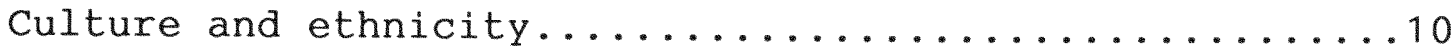

How are professionals dealing with diversity $\ldots \ldots \ldots 17$

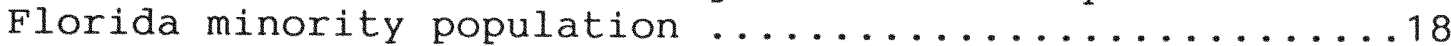

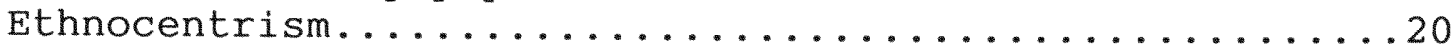

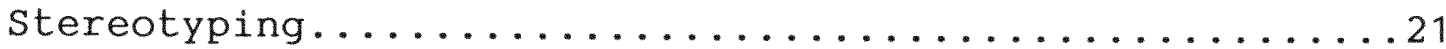

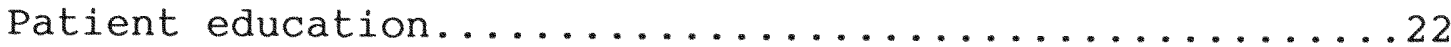

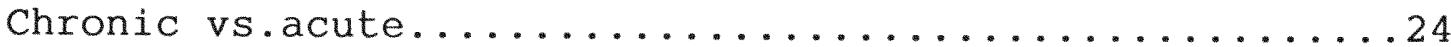

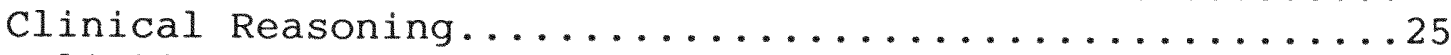

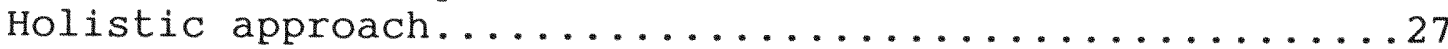

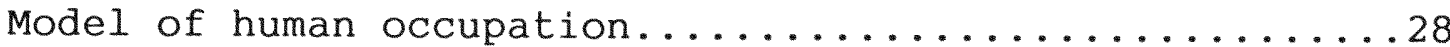

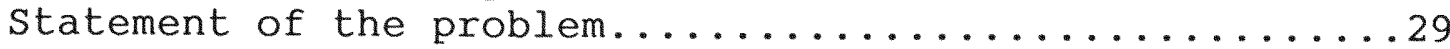

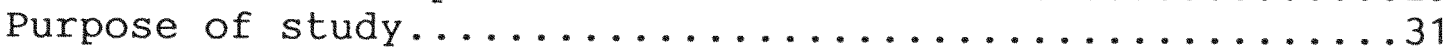

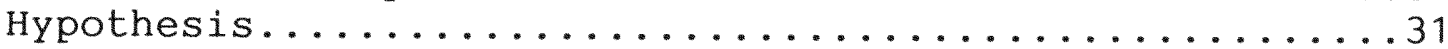

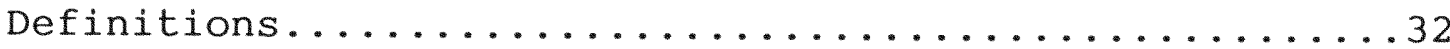

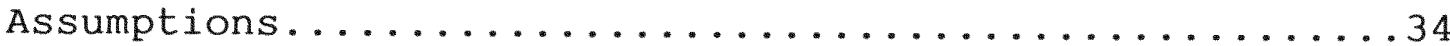

CHAPTER III

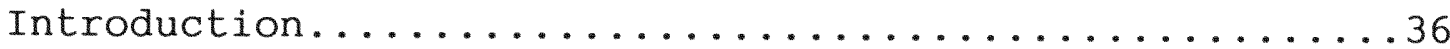

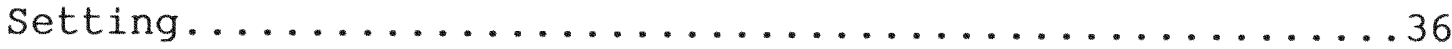

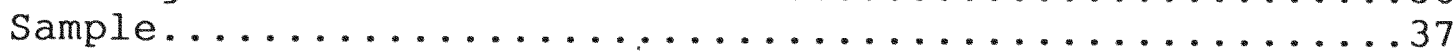

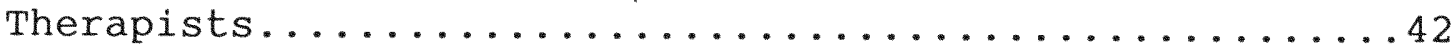

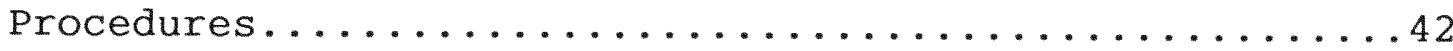

CHAPTER IV

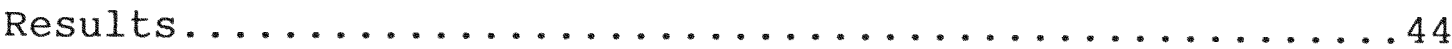

CHAPTER V

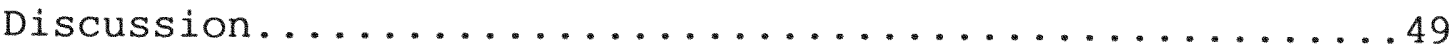

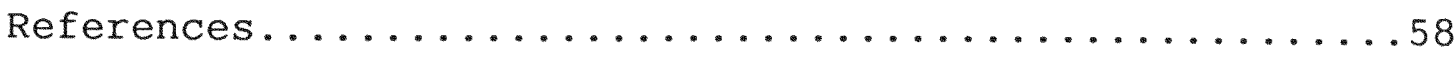

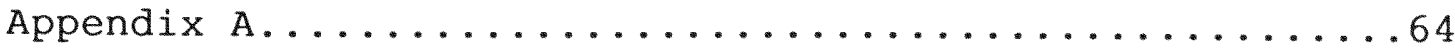

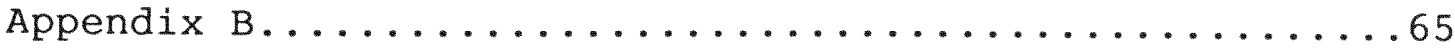




\section{CHAPTER 1}

\section{Introduction}

Occupational therapists come from a tradition that supports the importance of addressing all aspects of a person's life to provide effective treatment. When differences in language, culture, and ethnicity exist between patients and therapists, treatment effectiveness may be at risk. Language cannot be understood separately from culture and ethnicity, and while culture and ethnicity can be understood and respected, language differences establishes a communication barrier that can impede treatment. This paper discusses the influence of language, culture, and ethnicity on treatment outcome by studying the effect of treatment on a language barrier between therapist and patient. Consideration is given to the chronicity of the condition for which an individual is being treated. It is believed that patients' education and subsequent adjustment to medical condition may be compromised if a common language is not shared.

\section{How does cultural diversity affect health care?}

The world is composed of many diverse groups of people. America has often been erroneously referred to as a melting 
pot, where people from countries all over the world have come together. In reality the melting pot has never truly occurred. Instead people bring different values, cultural traditions and ethnic beliefs, making the population in the United states pluralistic and to some degree unique. In some parts of the United States, immigration occurred generations ago, resulting in greater homogeneity of cultural traditions. In other areas of America, primarily large cities, groups of first-generation immigrants and communities of people are often quite diverse in language and culture. Consequently, a variety of communities of cultures from all parts of the world are represented. This cultural variation makes up the diverse population in America. America's diverse society resembles a patchwork quilt with an increasing number of subcultures coexisting in the same community.

The more recent immigrants are as likely as any person to be a prospective patient and receive treatment in today's health care system. Factors such as culture, ethnicity, health care beliefs, trust, motivation, and endless other components are difficult to address when a patient and therapist do not have common language, culture or ethnicity. Language is believed to be one of the most essential factors in establishing the therapeutic relationship, for without common language, communication is obstructed. 
Demographers estimate that by the year 2000, Hispanics will be the largest minority population in the nation (Current Population Reports, 1993). Others predict that by the same year, 30 percent of the population will consist of persons from African American, Hispanic American, Asian and Native American backgrounds (Meadows, 1991). Therefore, changing demographics mean that our society must increasingly learn to serve the needs of clients from varying backgrounds. Along with differences in backgrounds may come variations in language. Therapists, doctors, and other health care workers who are unable to communicate effectively with patients because of differences in language may compromise treatment effectiveness. The impact of language barrier are many, including a potential for service to be perceived by patients as unsatisfactory.

The need to address language differences is particularly important to occupational therapists, as competent practice is integrally tied to both effective communication of information and the development of a therapeutic relationship. Intervention to increase functional independence and life satisfaction is the primary goal of the occupational therapist. This goal may be hampered when patients and therapists speak different languages and have distinctly different beliefs and values. 


\section{Ethnic variation}

Health practitioners can no longer ignore language, cultural, and ethnic differences in a multicultural society. Sensitivity to, and recognition of needs and uniqueness of individuals is essential in order to provide effective treatment. Generalizations about different ethnic groups often have some basis of fact. However, differences in ethnicity may cause practitioners to discount individuality and as a result jeopardize the adequacy of treatment. "While satisfying one's need to organize the unknown when employing such generalizations we run the risk of stereotyping" (Blackney, 1991). Therapists must learn to exercise caution in forming views of people who speak a different language and hold different values and beliefs. It is essential for therapists to recognize ethnic variation because every person brings a unique cultural tradition that forms the way the world is viewed. To fail to recognize differences among and between people is to deny the presence, richness, and the variability of tradition, thereby possibly affecting successful treatment outcomes. 


\section{Significance of study}

Through sensitivity and therapeutic use of self, a therapist who is cognizant of individual values, traditions, and language, can overcome barriers and provide effective treatment. Historically, those individuals that provide medical services in this country have been primarily members of the white majority portion of the population. Occupational therapists are no exception. Sources report that ethnic minorities represent between 7.2 and 9.0 percent of registered occupational therapists (AOTA, 1994 \& Evans, 1992). The majority therapists may not be able to communicate in a language other than English or be familiar with the values and belief system of other ethnic and cultural groups. The possibility exists that therapists may perceive and treat their patients according to their values, and beliefs. Occupational therapists must, ask themselves if the treatment provided to individuals of different language, ethnic, and cultural backgrounds is meeting those individual's needs. Are practitioners meeting the goals of their clients, or are practitioners focusing on the goals that they perceive as important? Are the cultural values and language spoken by the patient taken into account when the therapist sets goals for treatment? How can occupational therapists be sure? These 
questions need to be explored as therapists prepare themselves for competent present and future practice in an increasingly diverse society. Finding answers to these questions is difficult as the relationship between individual differences and successful treatment is complex indeed.

Effective communication is believed to be critical for a productive relationship between the therapist and patient. Effective communication is not possible when patients and therapists do not share a common language. When the treatment process is not productive then communication typically stops. This may occur either because a patient stops coming for treatment or the therapist does not continue to schedule treatment. Whatever the reason, the therapeutic relationship does not continue. A direct measurement of this therapeutic relationship is difficult, but a proxy measure could justifiably be length of treatment or number of visits.

This study examines the relationship between length of treatment, number of visits, and language spoken by therapist and patient. Length of treatment and number of visits are variables thought to reflect adequacy of treatment. In order to control for diagnosis as it might impact length of treatment and number of visits this study will further examine acute and chronic conditions of the patients. It is expected that patients diagnosed with a chronic condition will receive 
treatment for a longer period of time. It is also believed that patients with chronic conditions are more in need of lifestyle adjustment and education about the disability, which is dependent on cultural sensitivity and effective communication. Thus, this study separates patients into two groups, those with acute and those with chronic diagnoses. This establishes a natural division within which one can examine the effects language barriers may have on length of treatment and number of visits to therapists. In summary this study seeks to answer the question does variation in language effect length of treatment or number of visits in patients with either acute or chronic conditions? 


\section{CHAPTER II- Review of the Literature}

\section{Language}

Effective communication forms the groundwork for building a therapeutic alliance. This is especially important for a therapist who wishes to build a sound relationship with a patient. Occupational therapists planning treatment for patients who speak a different language face many challenges. First, the health care professional may perceive the patient as indifferent and noncompliant. Secondly, misinterpretation of information may occur. Finally, lack of rapport may reduce the chance of adequate and efficient treatment with unsuccessful outcomes for the patient. When the therapist and patient speak different languages, communication is hindered. As a result, the effectiveness of treatment may be obstructed because tasks such as interviewing, setting goals, building rapport, working with families, and receiving feedback from the patient are affected by this situation. In contrast, patients and therapists who speak the same language have the potential for more successful treatment outcomes.

A language barrier creates difficulty in communicating treatment objectives as well as understanding the patient's perception, feelings, and beliefs about occupational therapy. One solution proposed by Huttlinger, (1992), was that health 
care providers acquire knowledge of the language and communication patterns associated with the patient so the treatment is meaningful. Therapists must not only be able to communicate with patients but also to understand why a person is complying or not complying with the treatment regime. The inability to communicate verbally will make compliance difficult to assess. The therapist should consider a variety of factors to overcome the obstacle of the language barrier. Many times translators are readily available in a facility; when a translator is not available the situation becomes more difficult. The use of a translator is still a compromise because a translator could hamper the communication process. The translator may relay the information inappropriately despite clear attempts expressed by the therapist to be objective (Hatton, 1992). Meyers, 1992 indicates in her study that having trained interpreters is much more helpful than using a family member. A family member may not be the best choice because the individual is not an objective participant. In summation, language is a factor that is of utmost importance in building and maintaining a sound relationship between patient and therapist. The patient will be more at ease in dealing with lifestyle changes if they can communicate their expectations and thoughts to the therapist. Transmission of information permits education, facilitates the healing 
process, and makes for a more successful and therapeutic relationship between patient and therapist, thus promoting successful treatment outcomes.

\section{Culture and ethnicity}

When discussing the relationship between ethnicity and culture it is easier to talk about the similarities than the differences because they are so closely related. When people come from or share the same ethnic background they also embrace many of the same cultural traditions. It can also be said that if similarities of cultures are present so will resemblance in ethnic backgrounds. Although there are differences between ethnicity and culture the focus will be placed on the connection and affiliation between both of these topics not the differences.

Ethnicity refers to a group of people who may speak a different language than the dominant group. Ethnicity can include those individuals whose value system, accents, geographical locations, economic and political views differ from the majority group.

Cultural and ethnic awareness and sensitivity to differences in peoples background need to be integrated as part of occupational therapy practice in order to assure a 
therapeutic approach. Because humanity has many, varied cultures over the earth that range from simple illiterate societies to complex literate societies this integration and understanding of different cultures becomes more difficult. A person's cultural and ethnic background can make a significant difference in the approach a therapist takes, as culture and ethnicity affect and influence every aspect of health care. Awareness of the convictions of a patients' ethnic group can increase therapists' knowledge base and assist therapists in providing treatment this is beneficial to the patient.

It is difficult to talk about language without addressing both culture and ethnicity because each is an important component of the other. The literature suggests that therapists who appreciate the culture of the family or individual are in a position to intervene and create more effective treatment plans than those who do not (Blackeney, 1991) .

One way therapists may make treatment meaningful and relevant to patients' cultural backgrounds, is by using a multicultural approach in which all concerned individuals participate in their treatment. For example some therapists will respect the fact that an orthodox Jewish male may prefer to be treated by a male therapist rather than a female therapist. When treating an elderly person from the 
Philippines, the therapist should take into account the strong emphasis placed on family values and consider those values and obligations the family holds to make that elderly family member comfortable and happy. Furthermore, therapists should become more aware of their own culture so that they are able to identify their values and ideals, and separate personal cultural relevance from cultures of others. Integrating cultural knowledge and skill when establishing a treatment protocol will result in a more positive therapeutic relationship. Education in multicultural issues improves the competencies of occupational therapists. Educational and training programs are being implemented by occupational therapists to examine how culture and ethnicity influence the therapeutic relationship (Ottavi, Pope-Davis, \& Dings, 1994). One focus of these training programs is to give the therapist more insight into understanding the individual, through sensitivity to gestures and facial expressions as a medium of communicating nonverbally. Therapists in the study stated that when treating patients that did not speak the same language as they did, paying closer attention to subtle gestures expressed by the patients was one way to communicate and understand their situation better.

Cross-cultural assessments for individuals who may not be considered the "norm" or have not adapted into mainstream 
culture, are another way members of the health care system address the evolving situation of language and cultural diversity in the medical field. Part of the cultural assessment includes using observational skills to accomplish the task of strengthening the therapeutic process between patient and therapist (Meyers, 1992), to help minimize obstacles encountered through cultural variation. To handle complications of cultural and language differences within the patients' home environment, therapist's should become familiar with the patient's daily tasks. This can be accomplished by gathering information provided by family members and using them as interpreters if the situation calls for it.

Development of culturally sensitive assessments for use in Third World countries (Indonesia, India and Bangladesh), is also of interest to the occupational therapy profession (Krefting, 1992). In developing assessments for Third World countries practitioners in Western society, must always be cognizant of ethnocentrism or the belief that one group is superior to another. The use of standardized tests poses difficulties in observing patients in their own cultural environment and may give therapists a distorted view of the patients' abilities (Spencer, Krefting \& Mattingly, 1992). Norms for interpretation are usually established for the mainstream society. Therapists must be alert to the 
populations for which reliability and validity have been established prior to using an instrument in a standardized manner. Furthermore, assessments appropriate for members of mainstream America, may not be valid in other societies. Independence is a factor highly valued in western culture. This notion of independence is not as strong in other cultures where the family members' roles may be to take care of a disabled person and these duties are executed without hesitation by the family members. Yet in western culture emphasis is placed on a disabled person's ability to live and perform daily activities as independently as possible. "Our therapeutic models are themselves reflections of the culture in which they develop" (Pearce, 1982). Modifications in therapists" ways of thinking and attitudes when assessing a client need to be made. This is the first step in the development of cross-cultural occupational therapy (Kinebanian \& Stomph, 1992).

There are methods available to increase cultural sensitivity. Interventions to help sensitize therapists to the growing number of immigrant patients include: providing departmental in-service training, examining protocols and making necessary revisions, identifying ways in which to secure continued awareness of an individual's cultural needs, and encouraging staff members to learn activities that will 
enhance their ability to interact with people of different ethnic and cultural groups (Barney, 1991).

Dillard, (1992) presents multicultural models for staff members understanding of cultural differences. The goals of these programs; "The Asian Focus Program, The Latino Focus Program, and The African Peoples Focus Program" are educational. The purpose is for staff members to have a better understanding when communicating with patients from different ethnic and cultural groups, by actively participating in these programs.

Flaskeurd (1990) conducted a study that matched clients and therapists on variables such as ethnicity, language and gender. Although the findings were inconclusive, the author strongly suggested continuing research in cultural, language, and ethnic differences to heighten the knowledge therapists have, thereby enhancing the therapeutic process.

Studies about the diversity of patients from disparate parts of the world have been reported in the nursing literature. Consequently, a nursing curriculum developed a cultural awareness class to increase awareness on proper ways to approach patients of varied ethnic backgrounds (Huttingler, 1992). The class was an exchange program for students to have the opportunity to assess and care for health problems with families in other parts of the country. Recommendations were 
made for more of these programs to be implemented in the curriculum. Such programs exposed the students to other cultures and enhanced their world views of different groups of people. This experience may better prepare the students to work with patients in the future.

Considering the growing numbers of illegal aliens who immigrate to the United States (McCormak, 1987), researchers in one study found that it was important to incorporate into treatment principles techniques that reinforce intercultural communication and augment the interpersonal relationship between patient and therapist. A survey on racial considerations in occupational therapy indicated that Caucasian therapists used white middle class values as the standard by which they judged all of their patients (Shwaski, 1987). These therapists described their minority patients as being less motivated in the treatment. On the other hand, a small group of minority therapists from the same study indicated that they felt there were no differences in the patients they treated, despite cultural and ethnic differences. Some of the therapists interviewed reported that when they shared a common language, concerns from patients were easier to express to the therapist and vice versa. 
How are professionals dealing with the diversity in

\section{health care?}

The widely held belief of the past that one must mold the new employee to the ways of the predominant work culture has now been transformed to the belief that the main goal is accepting and understanding cultural diversity. Preferably, individuals should not be molded into the dominant cultural mores, instead, adjustments should be made to allow for diversity.

Some professionals respond to the problem of cultural, ethnic as well as language barriers by developing educational programs designed to increase insight and make occupational therapists more aware of people from different backgrounds. Steward (1991) describes a staff workshop designed primarily to educate nurses and administrators about the importance of recognizing culture when planning patient care. A second goal of the workshop was to train participants to consider similarities and differences among health care providers and patients from diverse cultures by listening with empathy, understanding the patient's perception of health and illness, and by identifying the cultural beliefs and practices affecting health care of a selected population. Finally, the workshop sought to identify situations where knowledge of 
cultural awareness could enhance a clinician's, specifically nurses, ability to provide culture-specific care (Stewart, 1991). For example, nursing supervisors and managers, may be encouraged to recognize and celebrate special days important to employees from different cultural and ethnic backgrounds. If the language, culture, and ethnicity are not acknowledged, it may be difficult to integrate mechanisms to deal with the diversity among the professionals, resulting in a tense and sterile working environment that jeopardizes the effectiveness of treatment.

Florida minority population and occupational therapists

The importance of addressing the issue of language and its impact on treatment becomes even more important with the growing numbers of immigrant minority groups in the United States. For example in South Florida the influx of Cuban and Haitian refugees is enormous. In the Miami area in 1991 there were 22,912 immigrants from Haiti, Mexico and the Dominican Republic (Table 1). In October of 1980, over 125,000 Cubans arrived in Florida. There was a 60 percent increase in the number of Cubans arriving to Florida in 1992-1993. There has been a 100 percent increase in the first eight months of 1994 
(Florida Refugee Handbook, 1994). Health care professionals provide treatment to many of these individuals. However, occupational therapy practitioners are typically of a different ethnic origin than the people they are treating. TABLE 1

IMMIGRANTS IN FLORIDA 1991

\begin{tabular}{|c|c|c|}
\hline rea of Birth & State of Florida & Miami and Hialeah \\
\hline Mexico & 42,928 & 5,192 \\
\hline Haiti & 30,375 & 15,996 \\
\hline Dominican Rep & 2,190 & 1,724 \\
\hline El Salvador & 2,064 & 1,070 \\
\hline Vietnam & 1,623 & 73 \\
\hline Philippines & 1,501 & 267 \\
\hline India & 1,224 & 243 \\
\hline Soviet Union & 759 & 370 \\
\hline Mainland China & 495 & 152 \\
\hline
\end{tabular}

Florida Statistical Abstract, 1994

The majority (91 percent) of the occupational therapist in the United States are still Caucasian (Table 2). In South Florida (Table 3) there are relatively more minority therapists, however 86.6 percent are Caucasian. The occupational therapy profession is attempting to deal with this disparity in representation of minorities by recruiting minority occupational therapy students, through availability of greater scholarship assistance, and eradicating racial barriers when hiring faculty (Evan, 1992). 
ETHNIC ORIGIN OF OCCUPATIONAL THERAPISTS AND OCCUPATIONAL THERAPY ASSISTANTS IN THE U. S.

\begin{tabular}{||l|c||}
\hline \multicolumn{1}{|c|}{ Ethnic Origin } & all OTR's (in percent) \\
\hline Caucasian & 91.0 \\
\hline Asian & 3.4 \\
\hline African American & 2.7 \\
\hline Hispanic & 1.8 \\
\hline American Indian & 0.2 \\
\hline Other & 0.8 \\
\hline Total & 99.9 \\
\hline
\end{tabular}

adapted from AOTA, 1994. Research Information and Evaluation Department.

TABLE 3

ETHNIC ORIGIN OF OCCUPATIONAL THERAPISTS IN SOUTH FLORTDA

\begin{tabular}{||l|l|l||}
\hline Ethnicity & number & valid percent \\
\hline Caucasian & 1393 & 86.6 \\
\hline Hispanic & 93 & 5.7 \\
\hline Asian & 72 & 4.5 \\
\hline African American & 45 & 2.8 \\
\hline American Indian & 5 & 0.3 \\
\hline No information & 112 & $\mathrm{~N} / \mathrm{A}$ \\
\hline Total & 1720 & \\
\hline
\end{tabular}

Member Survey data AOTA, 1994

\section{Ethnocentrism}

Ethnocentrism, the tendency toward cultural bias to one's group, is universally present and may influence the way a 
patient is treated. Ethnocentrism is the tendency to judge people, their environment and communication patterns according to the standard values and customs of one's own culture (Shwaski, 1987). Ethnocentrism exists in our society to a small or large degree, causing both positive and negative consequences in the health care system. Cohesion and unity among group members can be encouraged by ethnocentrism, but they can also contribute to attitudes of superiority, intolerance, and abhorrence for groups with different customs and beliefs. Therapists must develop an awareness and respect for the ethnic and cultural differences, values, beliefs, customs, and language patterns of the individuals they treat. "To work effectively one must believe intellectually and emotionally that in diversity there is strength" (Kerfoot, 1990). Evaluating others on the basis of one's own cultural tradition does not enhance human interaction. In fact it reduces the chances of appreciating the differences and similarities that make people special.

\section{Stereotyping}

Although stereotyping usually refers to an oversimplified way of viewing a certain group, to a limited extent it may help us understand similarities and differences among groups 
of people. Characteristics of differing ethnic groups illustrate how varied are cultural and ethnic traditions. These generalizations symbolize variability in values, roles, and personal goals. An understanding of these variations can enhance respect and understanding because each individual brings a cultural tradition, a tradition of orientation that forms the way the world is viewed.

\section{Patient Education}

Patient education is a major component in occupational therapy and becomes an important concern when treating patients who speak a different language. Therapists constantly teach, inform and educate patients on ways to enhance their current level of functioning in order to effectively deal with physical, emotional and/or environmental barriers. Educational materials in areas such as pain control, prevention, energy conservation techniques, and proper body mechanics, are available and provided to patients as part of the therapeutic and healing process. How much information is understood by the patient who does not speak the same language as the therapist? Even when materials are translated a question of great concern is the patient's comprehension of printed, educational information. One study focused on the importance of educating 
Hispanic patients about AIDS and showed that a language barrier limits access of information and may ultimately affect health care if the knowledge provided is not understood ( $\mathrm{Hu}$, Keeler \& Fleming, 1989). Effective delivery of health care is dependent on an elaborate mechanism that includes, among other components, communication between patient and doctor, as well as the ability of the patient to follow through with instructions (Woolley, Kane, Hughes, \& Wright, 1978). If the patient understands the information provided by the professional, the chances of compliance and satisfaction with the treatment outcome is greater.

Patient education may also be influenced by the experience of the therapists. If therapists are working with patients that do not share the same language, it may conflict with the information the therapist has to pass on to the patient. Another factor that also influences patient education is a therapist's patient load. With many patients to treat, time for each becomes limited and building rapport may be compromised. In a facility where an interdisciplinary approach is encouraged and quality of care is the main concern, the process of rendering information becomes easier if same language is shared.

There are endless other factors that in one way or another influence the educational process. Providing patients 
with educational information can be accomplished through pamphlets, written instructions, gestures, video tapes, illustrations, etc. With shared language, the distribution of information is facilitated and can be reinforced verbally thereby enhancing the educational process between patient and therapist.

\section{Condition: Chronic vs. Acute; Is there a difference} in treatment?

Communication between patient and therapist is the groundwork for building a therapeutic relationship. What happens when there is a language barrier between patient and therapist and that particular patient is diagnosed with a chronic illness such as cancer? The interactive mode of clinical reasoning, or the part of clinical reasoning that encourages and enhances communication between individuals is certainly compromised when a language barrier exists. In chronic conditions more verbal interchange is required because of the persistence of the condition and the way the condition affects performance of daily tasks. Considerable patient education is necessary for such individuals with chronic conditions. Therapists must then be prepared for the psychological and emotional component that inevitably follows when dealing with patients that have to live and cope with a 
chronic condition. Common language in the treatment of patients with chronic conditions is essential in communicating with the patient. However, when treating an acute condition, treatment may quickly maximizes a patient's current level of functioning, thus requiring less verbal exchange. If language is not shared when treating complex diseases, health care providers are unable to identify and administer culturally specific treatments, thereby contributing to noncompliance, frustration of health care workers, and ultimately less than adequate treatment. (Huttlinger, 1992).

\section{Clinical reasoning}

Clinical reasoning or the application of theory to practice is used in a variety of ways in the therapeutic process (Mattingly \& Fleming, 1994). Professionals use clinical reasoning on a daily basis, every time they are confronted with decision making situations. Mattingly and Fleming (1994) discuss how therapists think with a three-track mind, using procedural, interactive, and conditional modes of thinking. Procedural reasoning refers to deciding what treatment technique to use on a patient's presenting problem. Interactive reasoning occurs while the therapist develops more insight about the patient's response to treatment. Conditional 
reasoning is a more abstract process which integrates procedural and interactive reasoning to consider the patient in the context of their overall situation. Clinical reasoning reflects the therapist's experience, knowledge and approach to handling a situation. When responsible clinical reasoning is used the therapist treats the patient not the illness.

If a language barrier is present, interactive reasoning is compromised. When ethnocentricity occurs then conditional reasoning is compromised. These situations of language barrier and ethnocentrism becomes problematic because they influence clinical reasoning and clinical reasoning is essential for implementing effective treatment. Clinical reasoning starts from the minute a therapist analyzes and gathers information from the medical chart and continues throughout the entire length of patient treatment. The process of gathering information and planning appropriate discharge will be heavily impacted if common language is not shared. How will the therapist and patient confer and agree upon treatment plans? How will a therapist and patient communicate to learn about the prior history of a patient to discuss expected outcomes and discharge plans? This entire process will be impacted by the fact that common language is not shared between patient and therapist. 


\section{Holistic approach}

Several different theories or models guide the practice of occupational therapy. One theme or heuristic that links all models or theories is the idea of treating the entire person. In keeping with this holistic approach, therapist are trained to treat both the mind and body. This attention to holism is reflected in the third mode of clinical reasoning, the conditional mode. In the conditional mode the therapist considers how a person is affected by the illness. Taking a holistic approach is always more of a challenge when therapists are confronted with an individual whose language and cultural background differ from theirs. Practitioners need to know their own beliefs and values yet be sensitive to the language, cultural and ethnic beliefs of the patients they treat. Exploring with a patient their beliefs and perceptions as well as being familiar with what is important to them is critical to successful therapy.

The attention to culture is basic to the roots of occupational therapy. Occupational therapy founders incorporated the cultural aspect of a patients' life when planning treatment and believed that treating the mind and body was essential in meeting the need of the patients. That shift occurred in the profession in the early 1930's and then later in the 1960's another philosophical shift was attempted 
from the holistic emphasis to a reductionistic and medical model. The latter change was not successful and the holistic approach is still prominent within the profession of occupational therapy today, and it is best exemplified by the Model of Human Occupation (Kielhofner, 1992).

\section{Model of Human Occupation}

The Model of Human Occupation conceives of a human as an open system in constant and continual interaction with his or her surroundings. Such a perspective recognizes the fact that an individual's life is guided by daily interactions with the environment and that the environment influences the outcome of treatment. Kielhofner delineates four major environmental "layers" that affect the human system: objects, tasks, social groups and organization culture. Culture is the one "layer" most relevant to this discussion.

Culture in the model of human occupation addresses factors such as family structure, educational background, values, customs, beliefs, religion, political beliefs, and the physical environment. The culture component focuses on three subdivisions: nature, space/time, and transmissions of knowledge and values. Attention to these subdivisions helps the practitioner understand a patient's behavior, his or her 
history, the values the patient brings to therapy, and how the environment influences the person. Occupational therapists, because of their focus on daily life tasks, must learn to be knowledgeable and open minded about values, beliefs, religion, political beliefs, and the environment to be more effective in communicating and setting treatment goals with their patients. Applying the Model of Human Occupation, occupational therapists respect traditions of patients from different ethnic and cultural backgrounds. Developing cultural sensitivity is an ongoing process experienced in every therapist-patient relationship. Communication is an essential component of this theory base; otherwise an important chance to understand an individual's culture, beliefs, and values is compromised.

\section{Statement of the problem}

In order for effective treatment to take place a therapeutic relationship must be established. A therapeutic relationship happens when all individuals involved in the relationship are able to actively communicate. Communication is then significant in being able to understand an individual, to have respect for a person's values and beliefs, to learn and identify with their concerns, as well as to comprehend the 
family members perspective so that a sound treatment plan can be implemented. Unless communication can be established, the treatment will not be effective. One way of accomplishing this task is by sharing a common language. Common language enhances this therapeutic union as it allows for sharing thoughts, ideas, fears, and concerns. Common language facilitates the therapeutic process by aiding the therapist and patient to become familiar (with one another perspectives). It is crucial for the therapist to become knowledgeable about the patient's environment, as well as patient being able to describe for the therapist his/her current situation in order for appropriate treatment plans to be implemented. In South Florida this issue of common language is of concern because there are substantial communities of ethnic minorities. Some of these individuals in these communities do not speak English and, although Florida has relatively more minority therapists than other parts of the country, the situation exists where therapists treat patients who do not share the same language. 


\section{Purpose of the study}

This study examines the relationship between common language and patients' length of treatment and number of visits for two groups of patients, one group with acute conditions and one group with chronic conditions.

\section{Hypotheses}

\#1 Ho: Patient length of treatment does not vary if patients speak the same language or a different language than the therapist.

Ha: There is a significant increase in length of occupational therapy when the therapists and patients speak a common language.

\#2 Ho: Patients' length of treatment in occupational therapy is the same for patients with chronic and acute conditions.

Ha: There is significant increase in length of occupational therapy for patients with chronic versus acute conditions.

\#3 Ho: The number of occupational therapy visits does not vary if patients speak the same language or a different language than the therapist. 
Ha: Patients treated by therapists who speak the same language have greater number of occupational therapy sessions than patients treated by therapists who speak a different language.

\#4 Ho: Patients' number of occupational therapy visits is the same for patients with chronic and acute conditions.

Ha: There is significant increase in the number of occupational therapy visits for patients with chronic versus acute conditions.

\section{Definitions}

Terms such as ethnicity, culture, and race often have multiple subtle interpretations. To clarify, the following definitions are used in this study:

1. Ethnic refers to a group of people having distinctive characteristics in common, such as language, culture, history, race, or national origin "Primarily through interacting with others is when individuals better understand their own ethnicity," (Waters, 1990).

2. An ethnic minority is a group of people who differ in language, race, or color, national, religious, or cultural origins from the dominant group. The differing identity of an ethnic minority may be displayed in a number of ways including 
lifestyles, accents, language, value systems, and economic or political beliefs (Harwood, 1981).

3. Culture is a learned behavior acquired by individuals as members of a social group. "It is a multi-level concept which includes knowledge of beliefs, art, morals, law, customs and any other capabilities or habits acquired by man as a member of society" (Harwood, 1981). Culture is a "blueprint" for human behavior, which simultaneously influences a particular social group or society. It is a complex pattern of living learned through experience based on what people do, (cultural behavior), say, make or use (cultural artifacts), (Levine, 1987). Culture provides a group of people with appropriate and effective coping skills to interact with each other and the norms of their intrinsic environment.

4. Language is all the vocal sounds and written symbols representing them, that comprise a system by which the members of a nation, tribe, or other group communicate with each other 5. Language barrier occurs when individuals cannot communicate or express their thoughts effectively because they speak, read or write different languages.

6. Acute conditions are defined as mental or physical conditions that are temporary and do not have long lasting debilitating effects, e.g. simple fractures, laceration, carpal tunnel syndrome, hand injuries etc. 
7. Chronic conditions Chronic conditions are those that will have significant impact on an individual's lifestyle and long lasting effects on the person's performance of daily activities, e.g. arthritis, heart disease, cerebral vascular accident, amputation, cancer, etc.

8. Number of visits is the number of times a patient was seen for therapy in a three month period e.g. one time, five times, ten times, etc.

9. Length of treatment is how long a patient received treatment, whether it is 7 days, 10 days, 30 days, 45 days, etc.

\section{Assumptions}

1. To treat patients holistically, the therapist must be able to verbally communicate with the patient.

2. Therapists must appreciate and understand a patient's background, values, beliefs, and language in order to provide effective treatment.

3. To rehabilitate the patient, the therapist must understand and respect the patient's natural environment.

4. Treatment effectiveness depends both on communication and transmission of information. 
5. Number of visits or length of treatment can be viewed as a proxy measure for adequacy of treatment.

6. Patients diagnosed with chronic conditions will be treated for longer period of time and require more verbal dialogue than a patient diagnosed with an acute condition. 


\section{Introduction}

This retrospective study seeks to understand the relationship between shared language, and adequacy of treatment in occupational therapy. It is assumed that shared language enhances therapist-patient interaction, allowing movement beyond procedural reasoning. Therefore, one could assume that given similar presenting problems, patients who share a common language, with a therapist would remain in treatment longer than those patients who speak a language different from that of the therapist. Examination of patient length of treatment and number of patient visits as variables in this interaction may elucidate the role language plays in the therapeutic process. Moreover, assuming that chronic conditions necessitate longer treatment, it follows that those patients who experience chronic conditions should be seen for extended period of treatment.

Setting: Jackson Memorial Hospital is an Joint Commissions of Accreditation of Hospital Organizations (JCAHO) accredited, non-profit county/teaching hospital. In the past 76 years Jackson Memorial Hospital has been faced with recurring problems of overcrowding, financial constraints because of the 
large and diverse uninsured population and deteriorating buildings that require structural attention. The hospital has a total of one thousand five hundred and sixty seven licensed beds. The hospital is located on a 67 acre site that provides a comprehensive arrangement of diagnostic and various treatment services including those for medical, surgical, obstetrical gynecological, pediatric, psychiatric, emergent ambulatory and rehabilitation. Jackson Memorial Hospital employs a total of 13,675 employees, including physicians plus volunteers. Specifically, the occupational therapy department specializes in six areas, neurology, orthopedics, pediatrics, hands, burns, spinal injury, and psychology. There were 25 registered occupational therapist and 10 certified occupational therapy assistants employed at Jackson Memorial Hospital during the period of study september 1-November 30, 1993. The number of patients treated monthly by one therapist was approximately seventy-two.

Sample: There were five therapists treating outpatients, four spoke English only. Patients treated by these English only speaking therapists were included in the study. Two hundred and ninety-three subjects selected for this study received occupational therapy at the Jackson Memorial Hospital outpatient department between september 1, 1993 and November 
30, 1993. In the sample 42.5 percent of the patients were Hispanic, 35.6 percent were the African Americans, and 21.9 percent were Caucasian, (Table 4). Thus 57.5 percent of the sample was English speaking 42.5 percent of the sample were either bilingual or Spanish speaking only.

\section{TABLE 4}

DISTRIBUTION OF SAMPLE BY RACE

RACE
\begin{tabular}{||c|c|c||}
\hline Hispanic & 124 & PERCENT OF SAMPLE \\
\hline African American & 104 & $42.32 \%$ \\
\hline Caucasian & 64 & $35.50 \%$ \\
\hline Unknown & 1 & $21.84 \%$ \\
\hline Total & 293 & $.34 \%$ \\
\hline
\end{tabular}

In the sample of two hundred and ninety-three patients the proportion of male and female outpatients receiving treatment at Jackson Memorial Hospital was virtually the same. (Table 5). There were four more females than males.

TABLE 5

DISTRIBUTION OF SAMPLE BY GENDER

GENDER
\begin{tabular}{||l|c|c||}
\hline \hline Male & NUMBER & PERCENT OF SAMPLE \\
\hline Female & 143 & $48.81 \%$ \\
\hline Unknown & 347 & $50.17 \%$ \\
\hline Total & 293 & $1.02 \%$ \\
\hline
\end{tabular}


Almost half of those treated were twenty to forty years of age. (Table 6). The smallest age group of patients was children less than ten years old. The mean age of the total sample was 39.7 .

\section{TABLE 6}

DISTRIBUTION OF SAMPLE BY AGE

AGE
\begin{tabular}{||c|c|c||}
\hline$<10$ & 6 & 2.05 \\
\hline 10 to $<20$ & 22 & 7.51 \\
\hline 20 to $<30$ & 58 & 19.50 \\
\hline 30 to $<40$ & 65 & 22.18 \\
\hline 40 to $<50$ & 52 & 17.75 \\
\hline 50 to $<60$ & 57 & 19.45 \\
\hline 60 to $<70$ & 25 & 8.53 \\
\hline $70+$ & 8 & 2.73 \\
\hline Total & 293 & 100.00 \\
\hline
\end{tabular}

With regard to marital status, the largest percentage of individuals were single 47.8 percent. A smaller percentage $(n=29)$ were divorced followed by those persons who were married (22.1 percent). Almost 19 percent of the subjects were under 18 and specified no relationship or a nonmarital relationship (i.e. boyfriend, girlfriend, living together). (See Table 7, page 39). With regard to employment, over two thirds of the sample or 70.74 percent were unemployed.Aside from current employment status further investigation into type 
of occupation (Table 9), revealed that the subjects identified themselves with one of three occupational categories. These categories were service $(30.43 \%)$, labor $(27.54 \%)$, and other, including students $(42.03 \%)$. Subjects employment status and types of jobs held are consistent with the fact that Jackson Memorial is a county hospital that cannot deny treatment to anyone. Insurance status was not available, however, from reviewing the charts it appeared that the majority of the sample was uninsured.

TABLE 7

DISTRIBUTION OF SAMPLE BY MARITAL STATUS

\begin{tabular}{||l|l|l||}
\hline \multicolumn{1}{c}{ MARITAL STATUS } & PERCENT OF SAMPLE \\
\hline Married & 56 & $22.1 \%$ \\
\hline Divorced & 29 & $11.5 \%$ \\
\hline Single & 121 & $47.8 \%$ \\
\hline Other & 47 & $18.6 \%$ \\
\hline Total & 293 & $100.0 \%$ \\
\hline
\end{tabular}


TABLE 8

DISTRIBUTION OF SAMPLE BY EMPLOYMENT

EMPLOYED
\begin{tabular}{||c|c|c|}
\hline \hline Yes & 55 & PERCENT OF SAMPLE \\
\hline No & 133 & $18.77 \%$ \\
\hline Homemaker & 0 & $45.39 \%$ \\
\hline Unknown & 105 & $\sim 0$ \\
\hline Total & 293 & $35.84 \%$ \\
\hline
\end{tabular}

TABLE 9

DISTRIBUTION OF SAMPLE BY CLASS OF EMPLOYMENT

OCCUPATION
\begin{tabular}{||c|c|c||}
\hline \hline Service & 42 & PERCENT OF SAMPLE \\
\hline Labor & 38 & $14.33 \%$ \\
\hline Professionals & 0 & $12.97 \%$ \\
\hline Other/Students & 58 & $0 \%$ \\
\hline Unknown & 155 & $19.80 \%$ \\
\hline Total & 293 & $52.90 \%$ \\
\hline
\end{tabular}

The sample is almost equally male and female, mostly Hispanic and African American, not married, unemployed and in service and labor occupations, with eighty percent of sample at working age, 20-60. The outpatient occupational therapy staff consisted of five therapists, one of whom was bilingual, Hispanic. As this therapist did not experience a language barrier the patients seen by her were not included in 
this study. One therapist did treat four patients who spoke only Creole. Due to the small number representing that language the data was not included in the analysis.

Therapists: Each of the four therapists treating outpatients had between 3 to 14 years experience. Each therapist also had the opportunity to work in the different service areas of the occupational therapy department (orthopedic, neurological burns, hands, pediatrics, spinal cord and psychology. The attendance records of the four therapists that provided treatment for patients for the months of september, October and November, along with filling out a questionnaire (Appendix B), yielded the data needed to test the hypotheses.

Procedure: In order to obtain the data for this retrospective study, permission was granted from the Florida International University Human Subjects Committee as well as Jackson Memorial Hospital. This permission allowed the researcher to gain access to the medical records department. A staff member from the medical records department provided the charts requested. The time required to gather information from each chart varied from four to ten minutes depending on how complete or incomplete the charts were. To assure confidentiality each patient was assigned a case number. Data 
were gathered from the discharged record on the following variables: race, sex, age, diagnosis, occupation, employment, language, and marital status. Approximately 40 different charts were reviewed two to three times a week for approximately three and a half weeks. All subject information was recorded on form \#1, (Appendix A). Data were coded to identify the therapist who provided the treatment then all information was entered into the computer.

The data in this study were analyzed using statistical Analysis Software. First a correlational analysis was performed on the two dependent variables, the number of visits and length of treatment. The independent variable was language barrier.

Independent sample t-tests were performed to observe if there was a difference in length of treatment between subjects that spoke the same language as the therapists verses the subjects and therapists that did not speak the same language. The independent sample t-test was also performed to see if there was a difference in length of treatment between subjects with chronic or acute diagnosis. A systematic attempt was made, using a two way analysis of variance, to see if there was any relationship or interaction between length of treatment, diagnosis and language barrier. 


\section{CHAPTER IV}

\section{$\underline{\text { Results }}$}

The hypotheses that were tested in this study examine how length of treatment and number of visits affects adequacy of treatment. The relationship between length of treatment and number of visits was first explored to find out how closely they are related. If both factors (length if treatment and number of visits) were closely related, only one of the variables would need to be examined. The Pearson correlation coefficient $(.84)$ was found to be statistically significant $(p=0.0001)$, therefore, the focus of the analysis will be on the length of treatment to answer the first two hypotheses. Hypothesis \# 1

\#1 Ho: Length of treatment does not vary if patients speak the same language or a different language than the therapist.

Ha: There is a significant increase in length of occ pational therapy treatment when the therapists and patients speak a common language.

There was not sufficient evidence to reject the null hypothesis $(p=.4495)$, therefore an increase in length of treatment was not seen when common language was shared. (Table 10) 
TABLE 10

\begin{tabular}{|c|c|c|c|c|c|}
\hline 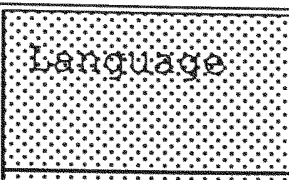 & का को & से & की & 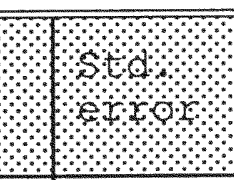 & मn' \\
\hline 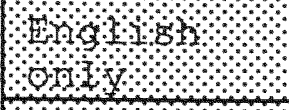 & 238 & 12.52 & 17.30 & 1.12 & $.899 *$ \\
\hline on & 53 & 12.84 & 16.61 & 2.28 & \\
\hline
\end{tabular}

*There is no significant one sided difference, $p>.05$.

Hypothesis \# 2

\#2 Ho: Length of treatment in occupational therapy is the same for patients with chronic and acute conditions.

Ha: There is significant increase in length of occupational therapy treatment for patients with chronic verses acute conditions. The one tailed p-value of .9875 in Table 11 shows that there is sufficient evidence to support the research hypothesis on the contrary the mean values on Table 11 show that the length of treatment was longer for those subjects with an acute condition. An exploratory independent sample t-test showed that the difference between these means was statistically significant ( $p=.025$ two tailed). 
TABLE 11

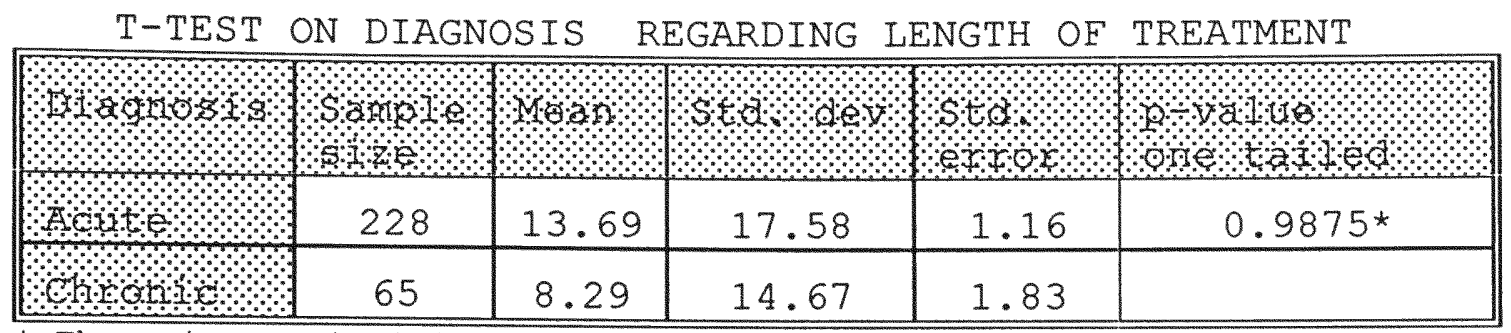

* There is no significant one-sided difference p >.05.

Hypothesis \#3 and \#4 will not be addressed because the Pearson Correlation revealed that their relationship between number of visits and length of treatment is high. Therefore, presumably length of treatment would yield the same results as number of visits and vise versa. Refer to hypothesis \#1 and \#2.

The results on Table 10 illustrate that there is not a significant relationship $(p=0.4495)$, between the mean values on subjects with or without a language barrier and the length of treatment. In other words if the patient and therapist do not speak the same language, length of treatment is not impeded.

Table 11 illustrates that there is a difference $(p=.025)$ between medical condition (acute verses chronic) and length of treatment. Length of treatment would be an indicator to support the concern that where a language barrier is present, adequacy of treatment is compromised. 
An interaction between length of treatment and diagnosis would support the concern that where a language barrier is present adequacy of treatment is compromised. Table 12 shows that there is no significant interaction $(p=.758)$ between the diagnosis and language barrier. The main effects of diagnosis and language barrier are also not statistically significant.

TABLE 12

ANOVA ON LENGTH OF TREATMENT WITH DIAGNOSIS AND LANGUAGE BARRIER

\begin{tabular}{||l|c|c|c|c|}
\hline \hline & af & $\begin{array}{l}\text { Mean } \\
\text { squares }\end{array}$ & F value & P value \\
\hline Diagnosis & 1 & 681.486 & 2.33 & .127 \\
\hline $\begin{array}{l}\text { Language } \\
\text { barrier }\end{array}$ & 1 & 24.56 & 0.08 & .772 \\
$\begin{array}{l}\text { Diagnosis and } \\
\text { language } \\
\text { barrier }\end{array}$ & 1 & 27.71 & 0.09 & $.758^{\star}$ \\
\hline
\end{tabular}

*There is no significant interaction, $p>.05$.

Since the results for diagnosis (acute verses chronic conditions) is counter intuitive, further investigation into the chronic group was executed to see if there were any differences between subjects with or without a language barrier and length of treatment. The results revealed that length of treatment was not statistically significant $(p=$ $0.699)$. 
See Table 13. In other words, within the chronic nature of diagnosis the presence or absence of a language barrier did not affect the length of treatment.

TABLE 13

T-TEST ON CHRONIC DIAGNOSIS LANGUAGE BARRIER REGARDING LENGTH OF TREATMENT

\begin{tabular}{||l|c|c|c|c|c|}
\hline $\begin{array}{l}\text { Language } \\
\text { barrier } \\
\text { size }\end{array}$ & Sample & Mean & Std. dev & Std. & P value \\
\hline $\begin{array}{l}\text { English } \\
\text { only }\end{array}$ & 52 & 8.057 & 14.78 & 2.05 & $0.699 *$ \\
\hline $\begin{array}{l}\text { Spanish } \\
\text { only }\end{array}$ & 12 & 9.916 & 15.75 & 4.54 & \\
\hline
\end{tabular}

Note. One patient out of the chronic group did not identify language, therefore, the subject was not incluaed as part of the analysis.

*There is no significant difference, $p>.05$. 


\section{CHAPTER V}

\section{DISCUSSION}

There are several reasons for investigating how language affects the outcome of health care, especially in an environment and community where a great majority of consumers speak a language different than those providing services. This is an issue affecting the profession of occupational therapy in south Florida, where there is not an accurate representation of therapists with regards to the population they treat. Thus choosing language as a medium to explore the hypotheses was one way of gaining further knowledge into this issue. Language is the primary way that people throughout the world communicate with each other. This communication is enhanced by shared ethnicity and culture. When common language does not exist, communication becomes difficult. The rehabilitation process is predicated upon effective communication between patient and therapist. We can imagine then, the challenge that exists for a patient and has been diagnosed with a chronic or acute condition and must deal with an ineffective communication between them and their therapist. This is essentially the situation explored in this study and although the results did not support the hypotheses that were tested, the following suggestions help explain why. 


\section{LANGUAGE BARRIER AND LENGTH OF TREATMENT}

This study examined the issue of how shared language is essential in the relationship between therapist and patient. It also considered common language, if present, how this factor will extend the length of treatment program. There was no significant relationship between language barrier and length of treatment. However, the general consensus shared by therapists in Jackson Memorial Hospital, was that speaking the same language as the patient enhances the relationship between therapist and patient, and because this did not occur it raises many other questions as to why the results did not show the expected pattern.

Practicing occupational therapists from Jackson Memorial Hospital offered varying responses to questions such as "How do you feel treating a patient that does not speak the same language that you do?", Do you feel that treatment is impeded? What are some of your frustrations, if any? How do you deal with them?" In essence, therapists felt that yes, treatment was impeded and frustration exists when common language is not shared. Therapists dealt with these obstacles by using a translator, learning key words or by transferring the patient to a therapist that spoke the same language. Nonetheless, some therapists felt that even with adjustments, rapport was still compromised. Minority therapists mentioned the fact that 
a strong accent also impeded patients' understanding of their instructions. The therapist agree that language does have a significant impact on building rapport and communicating with a patient. However, they also added that language is not the only factor that can block communication, language is the tip of the iceberg. When looking underneath there is an entire life of a person that needs to be acknowledged. This life includes a whole spectrum of the individual's experiences good and bad, values, beliefs, family dynamics, occupation and environmental influences, just to name a few. There is not one way of learning all of these different components that make up an individual, but it is extremely difficult if shared language is not present.

All of the therapists in the study reported that they were able to relay basic information to their Hispanic patient's but they had more difficulty with the Haitian population. They expressed the fact that no matter how hard they tried, language was not the only obstacle in gaining the patients trust to assist in the therapeutic process. The patient ideas of health care, value of the treatment plan, cultural experiences all have an impact on the relationship. Responses from the questionnaire (Appendix B) supported the role of insurance status on treatment length and frequency. The therapists response was "It does not affect 
the type of treatment the patient receives, but the number and frequency of treatments may be limited due to the individual's financial status". Occupational therapists do not handle the financial aspect of therapy, but they are becoming increasingly aware of the patients employment status because it is an indicator to length of treatment. For example, if a patient is unemployed, a ten dollar fee is required for every visit, however if a patient is employed, a payment system is calculated according to their gross income. Those individuals covered by Medicaid, other insurance, or can afford the 10 dollar fee, are the ones who consistently attend treatment sessions. Those who cannot are normally seen just one time. The therapists has to be aware of the patients financial situation in order to provide all of the essential information in one session and if a language barrier is present the efficacy of treatment adequacy is affected.

\section{CHRONIC VERSES ACUTE}

The supposition that patients with chronic conditions would have extended treatment periods did not prove correct. The significant relationship between treatment length and diagnosis showed the acute group having higher average length of treatment instead of the chronic group. This unexpected finding raises even more concern as it is the patients with 
more chronic conditions who were expected to be seen for longer education and development of adaptive skills. Even the therapists acknowledged that it was simpler to provide information to a patient without cognitive impairments. Further examination of the results showed that there was no significant relationship between language barrier and length of treatment within the group of patients with chronic diagnosis. Several explanations help clarify why language barrier did not have an impact especially when the patient was diagnosed with a chronic condition.

It could have been the short treatment time span cone to three months), the time period selected (September thru November), may not have been representative of the population usually treated at Jackson Memorial Hospital. Insurance coverage which is another confounding variable in the use of length of treatment and number of visits as indicators of treatment adequacy. The fact that 70 percent were unemployed, and potentially, therefore uninsured with limited financial resources for self pay can contribute to limitations in continued follow up. 
Preference for an individual to receive treatment at a different clinic, availability of transportation for the patients, experience of the therapist and their comfort level when treating patients with a wide variety of diagnosis intensified by the language barrier can

also help explain the results of the study.

\section{FURTHER EXPLANATION OF RESULTS}

Other factors that could have influenced the outcome of the data include patient compliance, inconsistencies of the information available from the charts. Since this is a retrospective study other individuals had collected the information available in the charts which allowed less opportunity to control the varialbles, and concern about deportation for some patients. Any of these factors rather than language barrier might explain the observed differences in subjects length of treatment in the outpatient department at Jackson Memorial Hospital. In addition, language is a highly complex issue and difficult to define due to the close affiliation with culture and ethnicity.

The literature review reflected the fact that the occupational therapy profession is aware of the growing numbers of patients that differ in language culture and ethnicity, especially when such a large proportion of the 
therapists are Caucasian and female. This is of concern because language is a complex and necessary part of communication. The emphasis should be placed on being open minded enough to accept, understand, and learn about differences, and similarities in language, culture and ethnicity. The therapeutic relationship which is a key component for effective treatment to occur will be at risk if therapists are not conducive to the idea of learning about and adjusting to the diversity of the population they treat. The results of this effort accentuate the fact that complex factors such as socioeconomic status, culture, ethnicity, patients' perception of the health care system, their values and beliefs are intertwined. Language is of concern in the treatment situation because it is the primary medium of communication and teaching patients. Common language is believed to be necessary for successful rehabilitation and treatment outcomes. Common language enhances the therapeutic relationship by bringing understanding of patients' fears, concerns, frustrations, and expectations. The fact that patients with acute conditions are treated longer that those with chronic conditions, may be an artifact of the problem. The setting was chosen for the multi-ethnic, multi-cultural population. 
Most of the patients in this population were found to be unemployed, and thus uninsured. Length of treatment as an indicator of adequacy of treatment to examine language proved overly simplistic.

\section{RECOMMENDATIONS}

Additional research on language barrier and how it effects treatment is necessary, along with further investigation into the dynamics of culture and ethnicity between the patient and therapist. Identifying educational resources, recruiting minority students and developing programs that enlighten individuals about different cultural and ethnic backgrounds can aide in the adjustment of diversity in our society. Interviewing patients on their perception of therapy and the health care system can help occupational therapists have a better representation of the groups of people they treat. The results of such inquiry may shed some light on factors important for productive, successful and effective treatment outcomes. This is key in making the therapeutic relationship work. "Nowhere is the importance of communication more apparent than in cross-cultural situations, where an occupational therapist or other health care providers work with people from a cultural background different than his or her own" (Huttlinger, et. al 1992). 
The intention of this project was to find an answer to the question "how does language affect the length of treatment in occupational therapy." It did not accomplish this goal, instead it promoted thought provoking questions that may or may not ever be answered because human nature is so umpredictable. The challenge of course is to face these individual situations so that one day the language culture or ethnic background of an individual will be simpler to interpret allowing uncomplicated interaction between individuals. 
REFERENCES

Academic American Encyclopedia.(1993). Grolier Electronic Publishing Inc.

An Asian Patient: (1991). How Does Culture Affect Care? Journal of Christian Nursing, 8 (3)46-47.

Attkisson, C.C., \& Zwick, R. (1982). The Client Satisfaction Questionnaire. Evaluation and Program Planning, 5, 233237.

Barney, K.F., (1991). From Ellis Island to Assisted

Living: Meeting the Needs of Older Adults from Diverse Cultures. American Journal of Occupational Therapy, 45 (7), 586-592.

Birrer, R. B., \& Weiner M. (1987). The Urban Environment and Its Impact on Primary Care. Medical Care, 25 (10), 10071010 .

Blackney, A. B. (1991). The Impact of Culture on Patient Education. Occupational Therapy Practice, 2 (3), 12-20.

Bollin, G. G. (1989). Ethnic Differences in Attitudes Toward Discipline Among Day Care Providers: Implication for Training. Child and Youth Care Quarterly, 18, (2), 111117.

Boyle, J. S. (1991). Transcultural Nursing Care of Central American Refugees. National student Nurses' Association, 38 (2), 73-77.

Buller, M. K., \& Buller, D.B., (1987). Physicians' Communication Style and Patient Satisfaction. Journal of Health and Social Behavior, 28, 375-388.

Carter, R.T. (1990). Cultural Value Differences Between African American and White American. Journal of College Student Development, 31, 71-79.

Christensen, C.P. (1988). Issues in Sex Therapy with Ethnic and Racial Minority Women. Women and Therapy 7, 187205. 
Cochran, S.D. (1986). Compliance With Lithium Regimens in the Outpatient Treatment of Bipolar Disorders. Journal of Compliance in Health Care, 1 (2), 153-167.

Current Population Reports, (1993). The Hispanic Population in the U.S. March 1986-1992. U.S Department of Commerce.

Dillard,M., Andonian,L., Flores, O., Lai,L., MacRae, A., \& Shakir,M.,(1992). Culturally competent occupational therapy in a Diversely Populated Mental Health Setting, American Jouranl of Occupational Therapy, 46, ( 8) $721-725$.

Dyck, I.(1992). Managing Chronic Illness: An immigrant Woman's Acquisition and use of Health Care Knowledge. American Journal of Occupational Therapy.,46 (8) 696-704.

Evans, J. (1992). What Occupational Therapist Can Do to Eliminate Racial Barriers to Health Care Access. American Journal of Occupational Therapy., 46 (8) 679683.

Flaskerud, J.H. (1990). Matching Client and Therapist Ethnicity, Language, and Gender: A Review of the Research. Issues in Mental Health Nursing, 11, 321-336.

Florida Statistical Abstract, 1994 p.58

Ford, R. (1987). Cultural Awareness and Cross Cultural Counseling. International Journal for the Advancement of Counseling, 10(1), 71-78.

Fountain, D.E. (1991). Battle Between the Gods: The Challenge of Transcultural Communication. Journal of Christian Nursing, 8(1), 27-30.

Hanson, M. J. (1990). Honoring the Cultural Diversity of Families when Gathering Data. Topics in Early Childhood Special Education, 10 (1), $112-131$.

Harwood, A. (1981). Ethnicity and Health Care. Harvard University Press.

Hatton, D. C. (1992). Information Transmission in Bilingual, Bicultural Context. Journal of Community Health Nursing, 9 (1), 53-59. 
Hu, D.J., Keller, R., \& Fleming, D., (1990). Communicating Aids Information to Hispanics: The importance of Language Media Preference, American Journal of Preventive Medicine, 5 (4) 106-200.

Huttlinger, K., \& Keating, S. B. (1991). Understanding Cultural Diversity Through a Student Exchange Program. Nurse Educator, 16 (5), 29-33.

Huttlinger, K., Kreftin, L., Drevdahl, D., Tree, P., Baca, E., \& Benally, A. (1992). Doing Battle: A Metaphorical Analysis of Diabetes Mellitus Among Navajo People. American Journal of Occupational Therapy., 46 (8) 696-711.

Jackson, J.S., Antonucci, T.C., \& Gibson, R.C., (1990). Cultural, Racial and Ethnic Minority Influences on Aging. Handbook of Ppsychology on Aging 3rd ed. Acdemic Press, Inc.San Diego Ca.

Jungersen, K., (1992). Culture, Theory and Practice of Occupational Therapy in New Zealand/Aoteroa.American Journal of Occupational Therapy., 46 (8) 745-750.

Kaplan, S., Greenfield, S., \& Ware, J.E. (1989). Assessing the Effects of Physician-Patient Interactions on the Outcomes of Chronic Disease. Medical Care, 27, (3) s110s127.

Kerfoot, K. M. (1990). Nursing Management Considerations. Journal of Nursing Economics, 8 (5), 354-362.

Kielhofner, G. (1992). Conceptual Foundations of Occupational Therapy. F.A. Davis Company, Philadelphia.

Kinebanian, A., \& Stomph, M. (1992). Cross-Cultural Occupational Therapy: A Critical Reflection. The American Journal of Occupational Therapy, $46 \overline{(8)}, 751-$ 757 .

Krefting, L. (1991). The Culture Concept in Everyday Practice of Occupational Therapy and Physical Therapy. Physical Therapy and Occupational Therapy in Pediatrics, 11 (4), 1-15. 
Kurtz, L. F. (1990). Measuring Member Satisfaction With Self Help Association. Evaluation and Program Planning, 13, 119-124.

Larsen, D.L., Attkisson, C.C., Hargreaves, W.A., \& Nguyen, T. D. (1979). Assessment of Client/Patient Satisfaction: Development of a General Scale. Evaluation and Program Planning, 2, 197-207.

Levine, R.E., (1984). The Cultural Aspects of Home Care Delivery. American Journal of Occupational Therapy, 38, 11 734-738.

Mattingly, C., \& Fleming M.H., (1994). Clinical Reasoning. F.A. Davis Company, Philadelphia, pp 117-197.

MCCormackG.L., (1987). Culture and Communication in the Treatment Planning for Occupational Therapy Minority Patients, Harworth Press, pp17-36.

McGoldrick, M., \& Rohrbaugh, M. (1987). Researching Ethnic Family Stereotypes. Journal of Family Process, 26(1), 88-98.

Meadows, M. L. (1991). Multicultural Communication. Haworth Press, Inc. 31-41.

Meyers, C. (1992). Hmong Children and Their Families: Consideration of Cultural Influences in Assessment. The American Journal of Occupational Therapy, 46 (8), 737744 .

Meleis, A. I. (1991). Between Two Cultures: Identity, Roles and Health. Healthcare for Women International, 12, 365-377.

Nguyen, T. D., Attikson, C. C., \& Stegner, B. L. (1983). Assessment of Patient Satisfaction: Development and Refinement of a Service Evaluation Questionnaire. Evaluation and Program Planning, 6, 299-314.

Ottavi, T.M., Pope-Davis, D. B., \& Dings, J.G., (1994). Relationship between white racial identity attitudes and self reported multicultural counseling competencies. Journal of Counseling Psychology, 41, (2), 149-154. 
Pearce, J.K., (1982). Ethnicity and Family Therapy. New York, Guilford Press.

Peterson, F. K. (1991). Issues of Race and Ethnicity in

Supervision: Emphasizing who You Are Not what You Know. Clinical Supervisor, 9 (1), 15-31.

Pollock, N. (1993). Client Centered Assessment. American Journal of Occupational Therapy, 47 (4), 298-301.

Roter, D., \& Hall, J., (1991). Health Education Theory: An application to the process of patient-provided communication. Health Education Research, 6, (2)185-193.

Rosembaum, J. N. (1991). A Cultural Assessment Guide. Canadian Nurse, 87 (4), 32-33.

Ruiz, P. (1990). Dominican Concepts of Health and Illness. Journal of New York State Nurses' Association, 21 (4), $11-13$.

Russell, K., \& Jewell, N. (1992). Cultural Impact of Health Care Access: Challenges for Improving the Health of African Americans. Journal of Community Health Nursing, 9 (3), 161-169.

Sands, R. F., \& Hale, S. L. (1987). Enhancing Cultural Sensitivity in Clinical Practice. Journal of National Black Nurses' Association, 2 (1), 54-63.

Sharf,B.F.(1990). Physician-Patient Communication as Interpersonal Rhetoric: A Narrative Approach Health Communication, 2(4), 217-231.

Shwaski,K.A.(1987). Ethnic/Racial Considerations in Occupational Therapy. Occupational Therapy in Health Care, $4,37-49$.

Smart, D.W., \& Smart, J.F. (1992). Cultural Issues in the Rehabilitation of Hispanics. Journal of Rehabilitation, 58 (2), 29-35.

Spencer,J.,Krefting, L., \& Mattingly, C., (1993). Incorporation of Ethnographic Methods in Occupational Assessment. American Journal of Occupational Therapy Assessment, 47 (4), 303-309. 
Stewart, B. (1991). A staff Development Workshop on Cultural Diversity. Journal of Nursing Staff Development 7, 190194.

Tein, J. L., \& Johnson, H. L., (1985). Black Mental Health Clients Preferences for Therapist: A New Look at an Old Issue. International. Journal of Social Psychology, $31(4), 258-266$.

Tullman, D.F. (1992). Cultural Diversity in Nursing Education: Does it Affect Racism in the Nursing Profession? Journal of Nursing Education, 31(7), 321324 .

Waters, M. C.(1990). Ethnic Options: Choosing Identities in America, University of California Press, 1990.

Wilson, L. L., \& Stith S. M. (1991). Culturally Sensitive Therapy With Black Clients. Journal of Multicultural Counseling and Development, 19, 32-43.

Woolley, R.F., Kane,R.L., Hughes, C., \& Wright D.D., (1978). The effects of Doctor -Patient Communcation on Satisfaction and Outcome of Care. Journal of Science and Medicine, 12, 123-128. 
APPENDIX A

CODESHEET

1. CASE \#- - -

2. RACE 1.WHITE 2. HISPANIC

3. AFROAMERICAN

4. HAITIAN 5. UNKNOWN

3. SEX 1. MALE 2. FEMALE 3. UNKNOWN

4. $A G E-$

$\begin{array}{lll}\text { 5. DIAGNOSIS }- & \text { 8. HAND INJURY } \\ & \text { 1. FRACTURES } & \text { 2. CANCER CARDIAC } \\ \text { 3. ARTHRITIS } & \text { 10. CVA } \\ \text { 4. GSW } & \text { 11. AMPUTEE } \\ \text { 5. CTS } & \text { 12. CHF } \\ \text { 6. SHOULDER } & \text { 13. ATAXIA } \\ \text { 7. CHRONIC PAIN } & \text { 14. ANEURISM }\end{array}$

6. LENGTH OF TREATMENT IN DAYS

7. \# OF VISITS

8. \# OF NO SHOWS(N/S)

9. WORKMAN COMPENSATION _ 1. YES 2. NO

$\begin{array}{ll}\text { 10. OCCUPATION }- & \text { 1. SERVICE 2. LABOR } \\ \text { 3. PROFESSIONAL } & \text { 4.OTHER }\end{array}$

11. EMPLOYED 1 - YES 2. NO 3. HOMEMAKER

$\begin{array}{ll}\text { 12. LANGUAGE } & \text { 1. ENGLISH } \\ \text { 3. CREOLE } & \text { 4. SPANISH }\end{array}$

13. MARITAL STATUS 1. MARRIED

2. DIVORCED

3. SINGLE

4. OTHER

Form 1 
APPENDIX B

\section{QUESTIONNAIRE}

1. What language(s) do you speak?

2. How do you fell language barriers affected the treatment you provide?

3. Do language barriers effect your treatment of some condition (problems) more than others?

4. How are patients assigned?

5. Do you tent to see some types of patients more or less than others as outpatient therapists? 